\title{
Cartografias afetivas e a ressignificação dos espaços e sensibilidades na urbe ${ }^{1}$
}

\author{
Cartografías afectivas y la resignificación de los espacios y sensibilidades \\ en la urbe
}
Affective cartographies and the redetermination of spaces and sensibilities in the city

\author{
Lucas Pereira Barros ${ }^{2}$
}

\begin{abstract}
Resumo
Este trabalho faz um breve histórico de como a revolução industrial e comunicacional na modernidade resultou numa perda de experiência autêntica e declínio da narrativa tradicional, como definidos por Walter Benjamin. Apresenta como o urbanismo surge enquanto prática e ganha protagonismo como forma de ação modificadora da estrutura das sociedades urbanas emergentes a partir do século XIX e analisa as experiências das diferentes errâncias urbanas que, concomitantemente, desejam pensar este novo espaço urbano moderno, desde as vanguardas históricas do início do século XX até as experiências de letristas e situacionistas nos anos cinquenta e sessenta. Munido destas referências históricas e teóricas, o trabalho busca no projeto de cartografias do cotidiano da associação The Worst Tours na cidade do Porto em Portugal uma das muitas vivências "neossituacionistas", capazes de oferecer experiências baseadas na arte do diálogo e da interação, inscritas na cotidianidade dos participantes. São tours não-turísticos pela cidade que revelam zonas fora dos guias tradicionais e proporcionam aproximações, trocas e descobertas, ativando dinâmicas coletivas e formas descentralizadas de experienciar o espaço urbano, a história e o presente de um povo. Conclui ressaltando a importância do espaço urbano enquanto espaço de troca e construção de novas formas de narratividade e rememoração a partir de um "tempo de agora", possível no exterior rugoso que é a cidade contemporânea.
\end{abstract}

Palavras-Chave: Cartografia; Cidade; Cotidiano; Exterior rugoso; Situacionismo.

\section{Resumen}

Este trabajo hace un breve histórico de cómo la revolución industrial y comunicacional en la modernidad resultó en una pérdida de experiencia auténtica y declinación de la narrativa tradicional, según lo definido por Walter Benjamin. Presenta cómo el urbanismo surge como práctica y gana protagonismo como forma de acción modificadora de la estructura de las sociedades urbanas emergentes a partir del siglo XIX y analiza las experiencias de los diferentes errantes urbanos que, concomitantemente, desean pensar este nuevo espacio urbano moderno, desde las vanguardias históricas de principios del siglo XX hasta las experiencias de letristas y situacionistas en los años cincuenta y sesenta. Armado con estas referencias históricas y teóricas, el trabajo búsqueda en lo proyecto de cartografía cotidiana de la asociación The Worst Tours en la ciudad de Porto en Portugal una de las muchas experiencias "neossituacionistas", capaces de ofrecer experiencias basadas en el arte del diálogo y la interacción, introducida en la cotidianidad de los participantes. Son tours no turísticos por la ciudad que revelan zonas fuera de las guías tradicionales y proporcionan aproximaciones, intercambios y descubrimientos, activando dinámicas colectivas y formas descentralizadas de experimentar el espacio urbano, la

\footnotetext{
${ }^{1}$ Artigo apresentado no Simpósio Temático Jovens Pesquisadores Latino-americanos (Graduandos) - Temática Livre durante o II Seminário Latino-Americano de Estudos em Cultura - SEMLACult em Foz do Iguaçu/PR, Brasil, 2018.

${ }^{2}$ Bacharel em Cinema e Audiovisual; Universidade Federal Fluminense - UFF; Niterói, Rio de Janeiro, Brasil; lpbarros93@gmail.com
} 
historia y el presente de un pueblo. Concluye resaltando la importancia del espacio urbano como espacio de intercambio y construcción de nuevas formas de narratividad y rememoración a partir de un "tiempo de ahora", posible en el exterior rugoso que es la ciudad contemporánea.

Palabras claves: Cartografía; Ciudad; Cotidiano; Exterior rugoso; Situacionismo.

\begin{abstract}
This paper gives a brief history of how the industrial and communicational revolution in modernity has resulted in a loss of authentic experience and decline in traditional narrative, as defined by Walter Benjamin. It presents how urbanism emerges as a practice and gains prominence as a form of action modifying the structure of emerging urban societies from the nineteenth century and analyzes the experiences of the different urban wanderings that, concurrently, wish to think this new modern urban space, from historical vanguards of the early twentieth century to the experiences of lyricists and situationists in the fifties and sixties. Armed with these historical and theoretical references, the paper searches in the daily cartography project of The Worst Tours in the city of Porto in Portugal, one of the many "neo-situacionists" experiences, capable of offering experiences based on the art of dialogue and interaction, inscribed in the everyday of the participants. They are non-touristic tours of the city that reveal areas outside the traditional guides and provide approximations, exchanges and discoveries, activating collective dynamics and decentralized ways of experiencing urban space, history and the present of a community. It concludes by emphasizing the importance of urban space as a space for exchange and construction of new forms of narrativity and remembrance from a "time of now", possible in the rugged exterior that is the contemporary city.
\end{abstract}

Keywords: Cartography; City; Daily; Rugged exterior; Situationism.

\title{
1. Introdução
}

Apreender a cidade contemporânea e falar sobre seu presente demandam um olhar crítico sobre o passado. Refletir sobre as consequências da modernidade, com a fundação e fortalecimento da sociedade urbana produto das revoluções industriais, permiti-nos entender as modificações que sofre a eticidade das comunidades urbanas ao longo dos últimos séculos, determinando novos valores que marcam a cotidianidade. A centralidade da liberdade e da individualidade, defendida pela nova classe dirigente a partir da modernidade - a burguesia traz novos olhares sobre o devir histórico e sobre o presente. As mudanças axiológicas promovidas pela burguesia dirigente estão diretamente relacionadas com o desenvolvimento do capitalismo industrial, que inaugura uma nova organização do trabalho responsável por uma crescente alienação do trabalho.

Associados aos novos estímulos que compõem a cidade moderna, todos estes fatores colaboram para uma verdadeira revolução na organização espacial das cidades e nas sensibilidades e comportamento cotidianos, modificando radicalmente a relação que havia previamente com a memória e tradição comuns. Para elucidar tais questionamentos, serão valiosos os textos teóricos de Walter Benjamin, como Experiência e pobreza, O narrador, O colecionador, Paris, capital do século XIX e A Modernidade e os modernos, bases para a 
discussão que traz as conjecturas do autor sobre o conceito de experiência, da forma como se vive o presente e nos relacionamos com o passado.

Interessa à pesquisa um resgate dos chamados errantes urbanos que surgem a partir deste novo cenário que é a modernidade, cujas experiências são cruciais ao inaugurarem um crescente interesse pelo detalhe e pelo fragmento como método de apreensão do cotidiano. Caminhando, portanto, na direção oposta de operações urbanísticas e políticas totalizantes e homogeneizantes, os errantes estão atentos às particularidades do heterogêneo terreno que compõe as cidades modernas. Seu primeiro representante é a figura do flâneur, que de meados e final do século XIX até início do século XX, criticava a primeira modernização das cidades e descobre esse novo espaço repleto de novas sensações.

As deambulações sucedem a flânerie e fazem parte das vanguardas europeias modernas - dadaísmo e surrealismo -, que criticam as ideias urbanísticas dos Congressos Internacionais de Arquitetura Moderna (CIAM) e propõem experiências físicas de errância no espaço real urbano (JACQUES, 2004). Em seguida, temos as derivas dos anos 1950-60, que correspondem ao pensamento urbano dos situacionistas, com sua crítica radical ao urbanismo e desenvolvimento da prática de deriva urbana, da errância voluntária pelas ruas, principalmente nos textos e ações propostos por Guy Debord, Raoul Vaneiguem, Asger Jorn e Constant Nieuwenhuys (Ibid.).

Munido deste quadro de referências históricas, iremos propor uma leitura sobre o projeto português The Worst Tours, que propõe caminhadas "não-turísticas" pela cidade do Porto em Portugal. Seguindo por caminhos poucos percorridos por guias turísticos, caminhadas temáticas percorrem o inconsciente da cidade e subvertem a ideia de turismo numa cidade que cada vez mais se volta para a prática turística, causando os fenômenos de gentrificação, aumento de alugueis e outras graves consequências para a dinâmica da cidade e de seus moradores.

A experiência dos The Worst Tours, como aquelas dos errantes urbanos, são importantes representantes de um outro entendimento do todo: inauguram novas formas de narrativas e experimentações do cotidiano a partir da reunião dos pontos de vista de seus variados participantes, demonstrando um entendimento da fragmentária estrutura social urbana característica das cidades contemporâneas. 


\section{As cidades}

O crescimento das cidades europeias durante meados do século XVIII e durante o século XIX, afetadas pelas revoluções industriais que se seguem, modifica gravemente a antiga organização social e econômica da sociedade que, se anteriormente se baseia em laços familiares, associações locais e na tradição (relações diretas e primárias), é substituída por relações indiretas baseadas em interesses ocupacionais e vocacionais (PARK, 1967). Para Debord (1997, p.173), “a história da cidade é a história da liberdade”, contudo, através de novos fundamentos - liberdade dos interesses privados, dos indivíduos agora subordinados à economia.

A cidade é a exteriorização destes novos sistemas de valores e de objetos que surgem mediante as transformações do desenvolvimento industrial e que correspondem às necessidades do grupo dominante, a classe burguesa, em oposição à massa de trabalhadores, o proletariado. Pautada no consumo de mercadorias e serviços, a sociedade moderna é aquela que satisfaz as necessidades individuais do homem urbanizado. A cidade é composta por uma heterogênea rede de elementos característicos do modo de vida burguês que consome sistemas urbanos de objetos - tais quais a água, a eletricidade, o gás, o carro, a televisão, utensílios de plástico, mobiliário - e elementos de sistemas de valores - como os modos de lazer urbano (danças, canções), os costumes e as modas (LEFEBVRE, 2001).

A revolução que acompanha a industrial nos meios de comunicação e transporte é significativa para essa acentuação da fragmentação das comunidades e para a valorização do homem individual. Tendo como efeito "substituir as associações mais íntimas e permanentes da comunidade menor por uma relação casual fortuita" (PARK, 1967, p.67), escolhe-se as comunidades através das quais se deseja expressar distintos conteúdos axiológicos, criando um movimento onde as comunidades existem através da própria individualidade dos seus indivíduos integrantes.

Heller (1970, p.73) aponta como o "homem converteu-se em ser social não necessariamente comunitário". O cotidiano é atravessado por indivíduos que não se conhecem; prevalência de relações secundárias que resultam na dita atitude de reserva: "os grandes números são responsáveis pela variabilidade individual, pela relativa ausência de conhecimento pessoal íntimo, pela segmentação de relações humanas as quais são em grande parte anônimas, superficiais e transitórias" (WIRTH, 1967, p. 122).

A captação dos novos estímulos sonoros e visuais que pululam nas cidades modernas - como o carro, bondes elétricos, ônibus, a iluminação a gás e elétrica - geram uma forma de 
experienciar definida por Benjamin (1975) como experiências de choque, interpretados pela consciência no que o autor classifica como experiência vivida. Característica do indivíduo moderno, consiste numa experiência pautada cada vez mais na interiorização dos fenômenos, numa forma de vivência absorta que privilegia a consciência individualizada. Próxima da definição de Simmel (1967), que o autor chama de "atitude blasé", que seria a atitude de reserva diante de tantas variáveis, como forma de autopreservação e imunização às exigências da vida metropolitana.

Se a experiência vivida consiste numa experiência que é fixada na memória com exatidão pelo estímulo abrupto, a experiência da tradição, em contrapartida, baseia-se em dados acumulados, de forma inconsciente, que afluem à memória (Op. cit.): são as memórias geracionais, ligadas à tradição oral, à escuta atenta e que se relacionam diretamente com a manualidade que se perde na modernidade com a crescente tecnicização e especialização do trabalho. Segundo o autor (BENJAMIN, 1987a), a narrativa floresceu num meio artesão - no campo, no mar e na cidade - quando o trabalhador tinha total controle sobre a sua produção e o próprio trabalho era um aprendizado pelo ouvir o outro, adquirido através da sabedoria do mais velho, que transmite ao mais jovem a sua experiência por provérbios, de forma concisa, ou através da narração de histórias, de forma prolixa, como explicitado por Benjamin (1987b) em seu ensaio anterior, Experiência e pobreza. A modernidade técnica revoluciona as relações de trabalho, pautada na crescente especialização do trabalhador, cujo trabalho maquinal e repetitivo faz com que sua mão se torne mais modesta (Op. cit.), o que influi diretamente sobre o enfraquecimento da narrativa tradicional.

Pois a narração, em seu aspecto sensível, não é de modo algum o produto exclusivo da voz. Na verdadeira narração, a mão intervém decisivamente com seus gestos, aprendidos na experiência do trabalho, que sustentam de cem maneiras o fluxo do que é dito [...]. A antiga coordenação da alma, do olhar e da mão [...] é típica do artesão, e é ela que encontramos sempre, onde quer que a arte de narrar seja praticada. (BENJAMIN, 1987a, p.220-221)

Igualmente, Benjamin (Ibid.) associa o declínio da tradição e da narrativa à atrofia que a própria ideia de eternidade sofre na passagem para a modernidade, marcada por um maior racionalismo e cientificismo nos mais diversos campos. Transformação que modifica a relação com a morte e que afeta a comunicabilidade das experiências à medida que a arte de narrar se extingue neste grande complexo criado pela revolução das forças produtivas. A faculdade de intercambiar experiências torna-se uma dificuldade quando a vida citadina se fragmenta, e onde o mote que movimenta tudo e todos afirma que a existência de um homem 
basta a si mesma. Nesta forma de experienciar o mundo, receber conselhos torna-se antiquado, precisamente pelas experiências estarem deixando de ser comunicáveis (Ibid.).

Será essa perda de comunicabilidade que explicará como o romance é a expressão literária que se adequa à modernidade, uma vez que o romancista é justamente a figura que, tal qual o homem moderno, se segrega. Tenta explicar o sentido da própria vida através de seus personagens (Ibid.) e deles o leitor irá apropriar-se para dar sentido à sua própria. O que distingue o romance de outras formas de prosa "é que ele nem procede da tradição oral, nem a alimenta" (Ibid., p.201). Pautada na continuidade e abertura das histórias, a narrativa é, em contrapartida, aquela que nunca se desgasta e que pode sempre ser atualizada: há um narrador que não priva o relato da própria experiência e, por isso, coloca a possibilidade de múltiplas interpretações, pois as histórias seguem seu curso continuamente através dos relatos subsequentes, afetados pelas experiências de quem fala.

A reação ao esfacelamento das narrativas tradicionais encontra expressão, portanto, no comportamento burguês de fins do século XIX. A arquitetura começa a valorizar o interior. Segundo Gagnebin (2011, p.59):

a casa particular torna-se uma espécie de refúgio contra um mundo exterior hostil e anônimo. $\mathrm{O}$ indivíduo burguês, que sofre de uma espécie de despersonalização generalizada, tenta remediar este mal por uma apropriação pessoal e personalizada redobrada de tudo o que lhe pertence no privado.

Quando Benjamin (1985, p. 38) diz que "habitar significa deixar rastros", faz alusão ao interior burguês que não é só o universo do homem privado, "mas também o seu estojo". Os objetos não têm mais valor de uso e são destacados de suas funcionalidades: liberados da obrigação de serem úteis (Ibid.), estão recobertos com o valor afetivo que o colecionador burguês imprime neles. O indivíduo que na modernidade encontra-se despossuído do sentido da vida, tenta desesperadamente, para Gagnebin (2011), deixar sua marca nos objetos pessoais: iniciais bordadas num lenço, estojos, bolsinhos, caixinhas, etc.

As experiências deixam de ser comunicáveis e os objetos adquiridos passam a ser eles próprios a experiência em si. O interior da casa burguesa, repleto dos vestígios da existência nos muitos objetos que povoam as prateleiras, é reduto de uma experiência de vida cada vez mais interiorizada: objetificação da experiência vivida, de consciências cada vez mais isoladas e retrato da incomunicabilidade que reina na modernidade. Este colecionador de memórias, cujo encantamento reside na inscrição particular do objeto em um círculo mágico no qual ele 
se imobiliza, deseja recordações práticas, mas que são proximidades resumidas. (BENJAMIN, 1987a).

\section{As vanguardas}

Artistas, escritores e pensadores que assistem às transformações da modernidade e que fazem parte desse complexo expressam o cenário e as novas problemáticas em suas obras. Em seus escritos encontramos reações críticas diretas e indiretas às intervenções urbanísticas que transformaram as velhas cidades, assim como reformulações da linguagem em si, que se adapta às novas sensibilidades de cidades marcadas pela fragmentação e pela multidão, esta última impondo-se como tema recorrente de literatos do século XIX e XX.

O movimento, a velocidade e as novas presenças urbanas já haviam se afirmado como mote das telas dos pintores e das páginas dos poetas na modernidade. O Impressionismo no século XIX, apesar de voltar-se para a representação de paisagens e não necessariamente de espaços urbanos, abre o caminho para a recusa das regras formais instituídas pela academia. Inicia-se a recusa de uma tradição cultural com a introdução de estéticas envolvendo novas experimentações e subjetividades que culminam nas múltiplas vanguardas no começo do século XX: interessam à pesquisa as investigações de dadaístas e surrealistas.

O dadaísmo propunha uma arte de protesto que procurou chocar a sociedade ao subverter os conceitos de arte vigentes, ao propor obras visuais e literárias baseadas no acaso: a colagem a partir de recorte; os ready-mades de Duchamp (que retira objetos industrializados de seu espaço funcional, assinando-os e exibindo-os em mostras de arte) revelam a atitude Dadá na desconstrução da linguagem tradicional da arte.

Segundo Careri (2013), será o dadaísmo que promoverá a saída do mote para uma experiência no espaço real, revelando o início do ato de explorar as percepções táteis, sonoras e visuais da cidade: no dia 14 de abril de 1921, dá-se o primeiro ready-made urbano, quando os membros do movimento que se forma em torno de André Breton se encontram em frente à igreja de Saint-Julien-le-Pauvre em Paris, dando início a uma série de excursões urbanas a lugares banais da cidade (Ibid.). Será com a operação Dadá que pela primeira vez se atribuirá um valor estético a um espaço vazio e não a um objeto.

$\mathrm{Na}$ inscrição espacial e temporal de suas ações ficam expressos o caráter simbólico e estético de suas investigações, cujas excursões se consolidam como críticas a cidade-fluxovelocidade e que desmascaram a farsa da cidade burguesa e provocam a cultura institucional 
(Ibid.). Com a sua quebra dos paradigmas artísticos, o dadaísmo abre espaço para o surgimento de novas vanguardas, como o Surrealismo, e décadas mais tarde, o Letrismo e o Situacionismo, onde se observam ações que exploram percepções sonoras, visuais e táteis na relação corpo-espaço, inscrevendo a vida cotidiana enquanto possibilidade estética.

Diferente da excursão dadaísta, a deambulação surrealista que surge quatro anos depois, opta por explorar territórios vazios, como bosques e campos. Em maio de 1924, Breton e seus companheiros dadaístas organizam uma deambulação em campo aberto da pequena cidade de Blois até Romorantin, escolhidas ao acaso (Ibid.). A caminhada que dura quatro dias consecutivos culmina no texto de André Breton, o Primeiro Manifesto Surrealista, que inaugura o movimento e define o termo como "automatismo psíquico puro com o qual se propõe expressar, seja verbalmente, seja por escrito, seja de qualquer outro modo, o funcionamento real do pensamento" (BRETON, 1924 apud CARERI, 2013, p. 78).

A deambulação campestre, todavia, transforma-se em deambulação urbana: deambular pelas zonas marginais das cidades torna-se uma das principais atividades dos surrealistas, que fazem a passagem dos territórios banais para os territórios do inconsciente (CARERI, 2013). Movidos pela nascente psicanálise, os surrealistas assumem que o espaço urbano comporta múltiplas realidades não visíveis, em vias de serem descobertas pelas deambulações, investigações psicológicas da própria relação com a realidade urbana proposta ao se atravessar a cidade.

As deambulações surrealistas, para além da produção de textos, manifestos e livros, inicia o processo de formalização da percepção do espaço sob a forma de "mapas influenciadores [...] baseados em variações da percepção obtidos mediante o percurso do ambiente urbano, em compreender as pulsões que a cidade provoca nos afetos do pedestre" (Ibid., p. 82). O método de construção de mapas afetivos será retomado nas experiências de Letristas e Situacionistas.

Décadas depois, o Letrismo, no início dos anos cinquenta, traz um novo termo para as pesquisas da realidade urbana: inaugura a dérive, uma atividade lúdica e coletiva que não só define as zonas inconscientes da cidade, mas que - valendo-se do conceito de psicogeografia, o estudo dos efeitos precisos do meio geográfico, conscientemente organizado ou não, que atuam diretamente no comportamento afetivo dos indivíduos (Ibid.) - pretende investigar os efeitos psíquicos que o contexto urbano produz no indivíduo (Ibid.). Se as deambulações surrealistas tratavam o espaço urbano como subjetivo-inconsciente, com múltiplas camadas 
de sentidos a serem descobertas, os letristas propõem um método mais objetivo de exploração. Para Careri (Ibid.), a importância dada aos sonhos pelos surrealistas, cuja fuga do real é uma forma reacionária que implementa outro uso da vida, é vista pelos letristas como uma incapacidade burguesa de realizar na realidade um novo estilo de vida. Os letristas procuram explorar a cidade, frequentam os lugares marginais, passam noites inteiras bebendo e discutindo revoluções, em ações que, segundo Careri (Ibid.), o consumo não deixa rastros: errâncias fugazes de instantes imediatos a serem vividos no presente, sem representações, uma atividade estética de antiarte.

Contudo, a errância letrista, caracterizada pela perdição juvenil, não mais satisfaz parte do grupo de Isidore Isou, numa cisão que funda a Internacional Letrista em 1952. Dentre seus integrantes, destacam-se as figuras de Guy Debord, Michele Bernstein e Gilles Ivain. Nos anos seguintes, o grupo amadurece suas investigações e formaliza teorias em torno das errâncias urbanas praticadas, em textos publicados de 1952 a 1954 no periódico Internationale Lettriste, e de 1954 a 1957, no boletim informativo onde Potlatch (JACQUES, 2003). Tratando de questões para se ir além da arte, passam a tratar da vida cotidiana em geral, da relação entre arte e vida, arquitetura e urbanismo e, sobretudo, de uma crítica ao funcionalismo moderno (Ibid.). Os letristas, sediados em Paris, passam a colaborar com artistas de outros grupos como a Associação Psicogeográfica de Londres (London Psychogeographical Association - LPA) e o grupo Cobra (Copenhaguem, Bruxelas, Amsterdã), culminando na criação da IS em 1957.

Na Internacional Letrista de Debord já se anunciam ideias, práticas e procedimentos que formam a base de todo o pensamento urbano situacionista, como a psicogeografia, a deriva e, principalmente a "construção de situações" (que dá nome ao grupo) (Ibid.). Durante seus doze anos de existência, o grupo permaneceria pequeno, com setenta integrantes ao longo dos doze anos de existência do movimento, com direito a expulsões de mais da metade de seus participantes por divergências internas (CARERI, 2013).

Após sua fundação em 1957, a IS passou a ter adeptos em vários países - Itália, França, Inglaterra, Alemanha, Bélgica, Holanda, Dinamarca e Argélia. Entre 1958 e 1969, 12 números da revista IS foram publicados e, se nos primeiros seis números (até 1961) as questões tratavam da passagem da arte para uma preocupação no urbanismo, posteriormente o grupo se volta para esferas propriamente políticas, e sobretudo revolucionárias, culminando na ativa participação situacionista nos eventos de Maio de 1968 em Paris (JACQUES, 2003). 
Debord, junto com os integrantes de outros grupos (LPA - London Psychogeographical Association e Cobra - Copenhaguem, Bruxelas, Amsterdã), como o dinamarquês Asger Jorn, o belga Christian Dotremont e o holandês Constant Nieuwenhuys, fundam o pensamento urbano situacionista (Ibid.). As pesquisas de seus integrantes propunham uma crítica incisiva ao urbanismo, ao entenderem seu papel crucial na modulação da realidade. Ao modificar o discurso urbanista, seria possível, então modificar a própria realidade e caminhar para o enfraquecimento do espetáculo e criar novos desejos.

A IS procura imergir no inconsciente urbano através de propostas práticas de pesquisa psicogeográfica. Uma teoria formal em torno do conceito da dérive, base do pensamento situacionista, surge um ano antes da criação do grupo, em 1956, com a Teoria da Deriva de Guy Debord. O conceito de deriva se liga ao reconhecimento dos efeitos de natureza psicogeográfica e à afirmação de um comportamento lúdico-construtivo (DEBORD, 2003a). A dérive (CARERI, 2013) é uma operação construída que aceita o destino, mas não se funda nele: estabelece antecipadamente, com base em cartografias psicogeográficas, as direções de penetração da unidade ambiental a ser analisada e a extensão do espaço de exploração.

As derivas do grupo não compunham única e somente uma procura por um outro estado na cidade, encerrando-se numa atitude individual, mas procuram mapear os modos de vida e analisar a relação dialética entre os ambientes e a constituição de formas distintas de organização e sociabilidade; em suma, investigar o inconsciente da cidade, nos pequenos detalhes ignorados por perspectivas funcionais. A Teoria da Deriva de Debord (Op. cit.) propõe a exploração de um campo espacial marcado pelo estabelecimento de bases e cálculo das direções de penetração, com o uso de mapas, sejam oficiais, sejam ecológicos ou psicogeográficos, e a correção e melhoria desses mapas.

Com o situacionismo, assiste-se a um retorno da busca pelo suprimido na cidade, explorado pelos surrealistas: procura-se revelar uma cidade lúdica e espontânea. O conceito de jogo serve como instrumento para a construção dessas novas situações desejadas, pois viam neste a oposição ao sistema capitalista dominado pelo tempo de trabalho em detrimento do tempo livre; um sistema que, inclusive, buscava constituir o tempo livre enquanto um espaço também de consumo, onde o trabalhador compra o que produz.

Buscava-se explorar o tempo não utilitarista através do jogo, uma construção de situações no explorar urbano capaz de suscitar nos indivíduos "novos comportamentos e de experimentar na realidade urbana os momentos do que teria podido ser a vida numa sociedade 
mais livre" (CARERI, 2013, p. 98). E através desta proposta que os situacionistas irão encontrar:

[...] o meio com o qual despir a cidade, mas também com o qual construir um meio lúdico de reapropriação do território: a cidade é um jogo a ser utilizado para o próprio aprazimento, um espaço para ser vivido coletivamente e onde experimentar comportamentos alternativos, onde perder o tempo útil para transformá-lo em tempo lúdico-construtivo. (Ibid., 2013, p. 98)

A sugestão de jogos espaço-afetivos por parte dos situacionistas aproxima a ideia de jogo e experiência estética - não à toa Johan Huizinga já era referência para a Internacional. Os situacionistas defendem a não distinção do jogo da vida corriqueira; o jogo torna-se a própria vida, numa completa mudança que quebra qualquer ficcionalidade a seu respeito: "seu objetivo deve ser o de, no mínimo, provocar condições favoráveis para viver a vida de forma mais direta. Neste sentido, ele é também luta e representação: luta por uma vida à altura do desejo, representação concreta dessa vida” (SITUACIONISTA, 2003a, p.60).

Os situacionistas percebem, igualmente, que não seria possível propor uma forma de cidade pré-definida, pois, segundo Jacques (2003), esta forma dependia da vontade de cada um e de todos, e esta não poderia ser ditada por um planejador: qualquer construção dependeria da participação ativa dos cidadãos. O modernismo prevê uma revolução arquitetônica; o situacionismo propõe a modificação das ambiências tal qual os modernistas, ao entender o caráter criativo das estruturas arquitetônicas, mas não sem antes entender de que forma os espaços se relacionam com seus participantes, aqueles que o ocupam. Ao contrário dos planejadores que desejavam pelas estruturas provocar (ou evitar) uma revolução, os situacionistas acreditavam que a própria sociedade quem deveria modificar as estruturas, cabendo ao situacionista usar a arquitetura e o espaço urbano como meios para induzir a participação ativa dos cidadãos e contribuir para a revolução da vida cotidiana contra a alienação e passividade da sociedade (Ibid.).

\section{The Worst Tours}

As ideias das errâncias urbanas se desenvolveram também no meio artístico após os situacionistas. Jacques (2004) cita o grupo neo-dadaísta Fluxus e os parangolés de Hélio Oiticica como exemplos de artistas que trabalharam no espaço público de forma crítica, vendo a cidade como campo de investigações artísticas aberto a novas possibilidades sensíveis, e 
assim, possibilitando outras maneiras de se analisar e estudar o espaço urbano através de suas obras ou experiências. A busca de artistas pós-situacionistas, como dito por Oiticica (1978 apud JACQUES, 2004), deseja "poetizar o urbano", seguindo nas investigações entre arte e vida cotidiana, que passam tanto por questões corporais quanto urbanas (Op. cit., 2004).

As caminhadas propostas no projeto The Worst Tours (TWT) - "Os Piores Tours" (tradução nossa) - da cidade do Porto, propõe caminhadas não-turísticas, onde o diálogo e interação entre guia e participantes constroem novas práticas sobre o conceito do turismo e apresenta a história da cidade e seu presente de maneira diferenciada da usual. Projetos que buscam novas formas de agenciamento, alimentando uma cultura situacionista baseada na arte do diálogo e da interação (SITUACIONISTA, 2003b) e que se inscreve na cotidianidade de seus participantes.

O The Worst Tours (TWT) procura criar novas formas de relação com as zonas da cidade através de diferentes excursões. Formado inicialmente em 2012 por um grupo de três arquitetos (Pedro, Gui e Isabel), hoje é uma associação independente que promove caminhadas pela cidade que podem ser agendadas pelo website do projeto. São sugeridas quatro rotas para escolha dos participantes, divididas em eixos temáticos. São elas: Caminhada na zona leste, As ilhas, Fontinha e Praça do Marquês e Rota romântica. Ao fim da caminhada, os participantes colaboram com uma ajuda monetária em valor definido por eles próprios.

O TWT joga o olhar para outros espaços da cidade, promovendo passeios turísticos diversos daqueles ofertados por outras empresas de turismo; rompe com o turismo aburguesado que explora centro histórico, restaurantes, lojas, adegas de vinho, museus, entre outros espaços que são o cartão-postal da cidade. As caminhadas propõem um explorar dessas outras zonas, voltam a atenção às memórias da cidade e do povo português, de ontem e de hoje, reavivando histórias que correm o risco de virarem rastros cada vez mais.

A Caminhada na zona leste discute a região esquecida por anos e que se tornou o próximo espaço de altos investimentos e renovações. Pretendem questionar a transformação dos prédios em hotéis e as consequências disso numa cidade cada vez mais refém do turismo. As ilhas procura discutir a história das formas de habitação que levaram este nome - "ilhas" criadas para serem moradias dos trabalhadores em casas oitocentistas da cidade; visitam-se antigas ilhas para discussão do que se tornaram. Fontinha e Praça do Marquês promove uma caminhada para discussão da relação entre uma escola primária do alto do morro da Fontinha e a biblioteca fechada na Praça do Marquês. E, por fim, a Rota romântica caminha em direção 
ao rio por antigas ruas mostrando as intervenções na região promovidas pelo Serviço de Apoio Ambulatório Local (SAAL), de construção de casas com participação pública.

Tive a oportunidade de realizar mais de uma caminhada dos TWT, realizadas pelo mesmo guia turístico, o arquiteto Pedro. Conheci o projeto ao visitar o quiosque do TWT localizado próximo ao Jardim de São Lázaro, aberto alguns dias da semana e que distribui o material gráfico sobre a proposta das caminhadas. Apesar da divisão em quatro eixos temáticos, o projeto está aberto às imprevisibilidades do grupo que se forma para as caminhadas. Se na primeira caminhada que fiz o eixo temático era Fontinha e Praça do Marquês, onde discutimos o projeto Espaço Colectivo Autogestionado (Es.Col.A ${ }^{3}$ ), que ocupou a escola primária fechada há anos no alto do Morro da Fontinha, isso não impediu Pedro de desviar e mostrar o Conjunto Habitacional da Bouça, projeto integrante do SAAL ${ }^{4}$, que faz parte da Rota romântica.

Meu guia do TWT, Pedro, relatou sobre a forma e fundação dos prédios históricos, caminhou por ruas escondidas mostrando a mim e outros participantes as muitas "ilhas" que marcam a cidade do Porto, discutiu a crise, a especulação mobiliária e a falsa revitalização dos prédios. Falamos das diferenças de ocupação do espaço público, num grupo diverso de portugueses, brasileiros e franceses, cada um contribuindo com suas histórias e observações. Apesar de parecer conhecer todas as ruas do Porto, por vezes Pedro se surpreendia, vendo um caminho que antes não vira. Seguíamos sempre um fluxo consciente, mas aberto às possibilidades, à imprevisibilidade dos nossos pés e à distração. Descobri lugares, adentrei o inconsciente da cidade em ações movidas pela força dos pés, para onde o olhar queria ver e o ouvido escutar. Um olhar mais atento me permitiu seguir caminhando e identificando novos detalhes que passaram despercebidos, como a Construção Social de São Victor, próximo de onde eu residia.

\footnotetext{
${ }^{3} \mathrm{Em}$ 2011, um grupo independente resolve ocupar a escola primária do Alto da Fontinha, abandonada há anos pela Câmara. De forma coletiva, o grupo promoveu atividades diversas voltadas à comunidade local. Expressivamente, as crianças tinham agora um espaço comunitário onde podiam ter acesso a grupos de estudo, jogos, oficinas de serigrafia, teatro, música, canto e atividades físicas. Meses depois, sem qualquer comunicado por parte da Câmara, a história do projeto termina com a triste ação da polícia, que encerra a ocupação, tornando o espaço novamente ocioso e abandonado.

${ }^{4}$ O SAAL foi um projeto arquitetônico criado poucos meses após a Revolução dos Cravos em 25 de Abril de 1974, que pôs fim ao regime ditatorial de Salazar em Portugal. O governo revolucionário procurou atender às necessidades das populações desfavorecidas através deste pioneiro trabalho que procurou criar novas formas habitacionais em diversas cidades do país onde muitos não possuíam as condições mínimas de habitabilidade.
} 
Na realização dos passeios não-turísticos pela cidade do Porto, novas perspectivas da cidade foram apresentadas, revelando [antigos] "novos" caminhos, escondidos, tesouros da cidade que não estão nos mapas comprados e que promovem discussões importantes sobre os rumos da cidade: história e política. Segundo o grupo:

\footnotetext{
Quem pode viajar, é turista, e queríamos nós que houvesse também o direito à viagem. Podemos sempre ser turistas em casa, e ir para fora cá dentro, do Aleixo ao lagarteiro, por vias travessas. Queremos discutir propriedade, gentrificação, emigração, trabalho, centro, periferia, quarteirões, história, política. Isto é um debate ambulante e um convite à imaginação. (TOURS, 2018)
}

Caminhadas que falam da passagem do tempo, da perda da memória, dos rastros que se apagam e do anonimato de regiões da cidade que não se encontram nos guias que se voltam para o núcleo urbano, extensamente povoado por intercambistas e turistas. Todos os participantes corporificam o flâneur de Baudelaire, deambulam como surrealistas nas zonas limítrofes da cidade ou derivam como letristas e situacionistas, observando e experimentando o espaço urbano de um ponto proposto ao outro.

Neste lado de fora, o que está em cheque são as identidades da cidade, e o projeto TWT deseja redescobrir tanto os percursos comuns quanto apresentar muitos outros, indo além das percepções óbvias da cidade, restrita ao centro histórico onde a gentrificação cresce desmesuradamente. O centro torna-se pobre em experiências, tanto para quem visita, quanto para quem habita, na medida em que os espaços assumem funções estanques, é planificada no projeto retratista da cidade em detrimento de um exterior que pode ser polifônico e onde prolifera a espontaneidade e criatividade dos indivíduos.

Os TWT apresentam a cidade por novos prismas a partir de uma psicogeografia coletiva, resultado da troca entre participantes e guia. Ação sobre o presente e vivência de um cotidiano alerta e coletivo. Abandona-se o interior burguês que acumula objetos dispostos à sua em defesa do explorar um exterior rugoso, feito de memórias compartilhadas e onde a própria arquitetura, seus componentes e viventes são o que há de maior valor.

\section{Conclusão}

O esfacelamento das comunidades primárias realiza um rompimento com a tradição, que é um rompimento de uma leitura do próprio presente. A mudança perceptiva e sensorial, fruto deste processo histórico, é a responsável pela pobreza que as experiências adquirem, como proposto por Benjamin (1987a), não mais vinculadas à tradição que marcava o 
conhecimento de diversas áreas do saber, como a política, a filosofia, as artes e as religiões. As experiências na sociedade tecnologizada são pautadas na crescente racionalização que valida a realidade, no saber científico e na comunicação a partir da informação verificável.

A rede na qual está guardada o dom narrativo, segundo Benjamin (Ibid., p.205), se desfaz hoje, após ter sido tecida por milênios em torno das mais antigas formas de trabalho manual: "ninguém mais fia ou tece enquanto ouve uma história", pois a mecanização do trabalho manual petrifica as relações entre estes três constituintes: mão, olhar e alma. A sujeição do indivíduo às forças impessoais da técnica acarreta este progressivo crescimento e transformação das vidas de forma tão rápida e total que não são mais assimiláveis pela palavra: as atividades são dominadas na atualidade pela categoria do ver (DEBORD, 1997).

A cidade moderna, sempre atualizada, é marcada pelo contraste entre estruturas novas e velhas, e estímulos sonoros e visuais que aprofundam a autopreservação, prejudicam a espontânea autoexpressão e senso de participação de uma vida social integrada (WIRTH, 1967), culminando na noção de experiência vivida, de vivências interiorizadas e incomunicabilidades.

Ao propor uma etnografia crítica do espaço, compreende-se o atual panorama das grandes cidades, com grupos fechados em pequenas existências, distantes do acaso e do outro; espaços cada vez mais domesticados, privatizados, condomínios fechando quilômetros de ruas, muros altos que escondem comunidades - discursos possíveis pelo controle midiático da informação que dissemina e alimenta a "periculosidade" do lado de fora.

O trabalho se encerra enquanto uma inquietude teórica que deseja apontar como pequenos fenômenos culturais são capazes de propor novas formas de sociabilidade, de modos de consumo e de lazer, criando comunicabilidades outras. O projeto apresentado lembra que a experiência é um momento de maravilhamento e trocas, lembrete daquilo que nos conecta e nos ativa ao espaço, ao outro: relembrar a existência do presente, obliterado pelo espetáculo, que nos subjuga a memórias involuntárias e transforma o presente numa corrida interminável feita de trabalho e pequenos prazeres, de realizações imediatistas e que conduz a uma atitude passiva diante do presente de nossas vidas.

Busca uma nova forma de agenciamento com o espaço citadino e também com a história e a memória: as caminhadas ratificam a fragmentação de pontos de vista, dos métodos particulares de rememoração de cada participante que integra cada grupo, que traz seu olhar e seu ponto de vista. $\mathrm{O}$ resultado é uma estrutura diversificada, feita a partir da multiplicidade que é a vida cotidiana, mas onde cada peça prova seu papel primordial na construção de um todo: o decurso da atualidade como a troca entre muitos. 
A fragmentação moderna não significa unicamente um processo de desencanto ou desagregação social (GAGNEBIN, 2011); vimos como estes dois estão ligados a processos históricos diretamente relacionados a evolução dos meios de produção e domínio do discurso hegemônico; e igualmente como o fragmento pode ser meio para expressar novas formas de expressão, tal qual as vias exploradas por todos os errantes urbanos. Ela abre portas para uma nova atitude perante nossa linguagem e história. As caminhadas do TWT aproximam-se do conceito do "tempo de agora" de Benjamin que, para Gagnebin (Ibid.), propõe o surgimento do passado no presente, um evento do instante.

Ela [a experiência] renasce sobre outra forma no agora, extrapolando o ver, este meio protagonista da filosofia ocidental que nos afastou daquilo que é palpável. Então estamos falando de uma história que lembra de seu passado, mas inscrita no presente e para o presente (Ibid.). Não como um historicismo que busca causalidade entre os momentos da história, criando a noção de um tempo infinito e interminável, de uma história com um decurso linear, mas através de uma rememoração que serve à atualidade. Benjamin deseja uma história descontínua que, diferente da habitual representação da história, niveladora, resgata os lugares nos quais a tradição/transmissão se interrompe e, com isso, suas asperezas e arestas (Ibid.).

Se a tradição não mais nos liga ao passado, talvez seja possível uma tradição do compartilhamento, criando um grande repositório onde todo lugar é acessível a um e a todos, onde cada canto guarda micro-histórias e microrrealidades que mudam constantemente, organismo vivo onde passado, presente e futuro não conhecem fronteiras. Lugar capaz de dar conta de um presente fragmentário, onde não há uma verdade de discurso, acolhendo, assim, o descontínuo da história que habita a porosa cidade contemporânea.

Ativa-se o corpo mais uma vez, sopra-se nos sentidos gentilmente, retirando-lhes do sono, nas pernas que correm velozes pelas ruas à procura de mensagens, na pausa em que se faz a pergunta e se responde, no espaço que se torna protagonista e cúmplice, no rastro que não está em objetos, no caminhar lado a lado, na escuta atenta que apreende histórias e insere as suas próprias, no explorar atento do cotidiano das mais variadas zonas das cidades, exterior rugoso, nunca liso ou homogêneo, mas múltiplo. 


\section{Referências}

BENJAMIN, Walter. A modernidade e os modernos. Tradução: Heindrun Krieger Mendes da Silva, Arlete de Brito e Tania Jatobá. Rio de Janeiro: Edições Tempo Brasileiro Ltda, 1975. (Obra Completa)

BENJAMIN, Walter. Experiência e pobreza. In: Magia e técnica, arte e política: ensaios sobre literatura e história da cultura. $3^{a}$ Edição. Trad. Sergio Paulo Rouanet. São Paulo: Editora Brasiliense, 1987b, p. 114-119. (Capítulo de livro)

BENJAMIN, Walter. $O$ narrador. Considerações sobre a obra de Nikolai Leskov. In: Magia e técnica, arte e política: ensaios sobre literatura e história da cultura. $3^{\text {a }}$ Edição. Trad. Sergio Paulo Rouanet. São Paulo: Editora Brasiliense, 1987a, p. 197-221. (Capítulo de livro)

BENJAMIN, Walter. Paris, a capital do século XIX. In: Sociologia. Trad. Flávio R. Kothe. São Paulo: Ática, 1985, p. 30-43. (Capítulo de livro)

CARERI, Francesco. Walkscapes: o caminhar como prática estética. Tradução: Frederico Bonaldo. São Paulo: Editora G. Gili, 2013. (Obra completa)

DEBORD, Guy-Ernest. A sociedade do espetáculo. Tradução: Estela dos Santos Abreu. Rio de Janeiro: Contraponto, 1997. (Obra completa)

DEBORD, Guy-Ernest. Teoria da deriva. In: JACQUES, Paola Berenstein (Org.). Apologia da deriva: escritos situacionistas sobre a cidade. Estela dos Santos Abreu (Trad.). Rio de Janeiro: Casa da Palavra, 2003a. p. 87-91. (Capítulo de livro)

GAGNEBIN, Jeanne Marie. História e narração em Walter Benjamin. São Paulo: Perspectiva, 2011. (Obra completa)

HELlER, Agnes. O Cotidiano e a História. $7^{\mathrm{a}}$ Edição. Trad. Carlos Nelson Coutinho e Leandro Konder. São Paulo: Paz e Terra, 2004. (Obra completa)

JACQUES, Paola Berenstein. Breve histórico da Internacional Situacionista. Arquitextos, São Paulo, ano 03, $\mathrm{n}^{\circ}$. 035.05, Vitruvius, abr. 2003. Disponível em: http://www.vitruvius.com.br/revistas/read/arquitextos/03.035/696. Acesso em: 26 jun. 2018. (Artigo em Periódico Digital)

JACQUES, Paola Berenstein. Elogio aos errantes. Breve histórico das errâncias urbanas. Arquitextos, São Paulo, ano 05, $\mathrm{n}^{\circ}$. 053.04, Vitruvius, out. 2004. Disponível em: http://www.vitruvius.com.br/revistas/read/arquitextos/05.053/536. Acesso em: 26 jun. 2018. (Artigo em Periódico Digital)

LEFEBVRE, Henri. $O$ direito à cidade. $5^{\text {a }}$ Edição. Trad. Rubens Eduardo Frias. São Paulo: Centauro, 2001. (Obra completa)

PARK, Robert Ezra. A cidade: sugestões para a investigação do comportamento humano no meio urbano. In: VELHO, Otávio Guilherme. O fenômeno urbano. Trad. Sérgio Magalhães Santeiro. Rio de Janeiro: Zahar Editores, 1967. p. 29-72. (Capítulo de livro) 
SIMMEL, Georg. A metrópole e a vida mental. In: VELHO, Otávio Guilherme. O fenômeno urbano. Trad. Sérgio Marques dos Reis. Rio de Janeiro: Zahar Editores, 1967. p. 13-28. (Capítulo de livro)

SITUACIONISTA, Internacional. Contribuição para uma definição situacionista de jogo. In: JACQUES, Paola Berenstein (Org.). Apologia da deriva: escritos situacionistas sobre a cidade. Trad. Estela dos Santos Abreu. Rio de Janeiro: Casa da Palavra, 2003a. p. 60-61. (Capítulo de livro)

SITUACIONISTA, Internacional. Manifesto. In: JACQUES, Paola Berenstein (Org.). Apologia da deriva: escritos situacionistas sobre a cidade. Trad. Estela dos Santos Abreu. Rio de Janeiro: Casa da Palavra, 2003b. p. 126-127. (Capítulo de livro)

TOURS, The Worst. Cumbite!!! (vai um passeio?). Disponível em: https://theworsttours.weebly.com/em-portuguecircs.html. Acesso em 20. Jun. 2018. (Modelo para Sites)

WIRTH, Louis. O urbanismo como modo de vida. In: VELHO, Otávio Guilherme. O fenômeno urbano. Trad. Sérgio Marques dos Reis. Rio de Janeiro: Zahar Editores, 1967. p. 97-122. (Capítulo de livro) 